\title{
Status of blue duiker (Cephalophus monticola) in the Lebialem-Mone- Banyang-Mbo landscape, South-West Cameroon
}

\author{
Martin N. TCHAMBA, E. Angwafor TSI, Derick Titih AFUH * and Joseph A. AWOH \\ Department of Forestry, Faculty of Agronomy and Agricultural Science, University of Dschang, Cameroon. \\ *Corresponding author; E-mail: afuhderick@yahoo.com; Tel: (+237) 675458011
}

\begin{abstract}
A survey of blue duikers (Cephalophus monticola) in the Lebialem-Mone-Banyang-Mbo (LMBM) landscape was conducted during the period of May to September 2012 with the aim of establishing a database for the enhancement of sustainable management of Wildlife population. The line transect method (Tsi, 2011) was used for data collection. Results revealed an encounter rate of 12.8 indexes per $\mathrm{km}$, a density of 2.56 per $\mathrm{km}^{2}$ and estimate of 1162 blue duikers in the entire landscape. The findings also showed that there is currently a high level of bush meat harvesting and a tragic forest transformation due to uncontrolled anthropogenic activities in the landscape. In comparison with the findings of Walhert in Korupt national park, the estimated density in the LMBM landscape was considered relatively high for a non protected area. It was concluded that this high population of blue duikers against a background of intense anthropogenic activities is indicative; It is strong evident that LMBM landscape serves as a natural wildlife corridor, linking it many surrounding protected areas. There the gazetment of the proposed Bechati- Mone wildlife corridor situated in the LMBM landscape will go a long way to enhance effective wildlife conservation in the region.

(c) 2015 International Formulae Group. All rights reserved.
\end{abstract}

Keywords: Conservation status, blue duiker, encounter rate, anthropogenic activities, sustainable management, wildlife corridor.

\section{INTRODUCTION}

Cameroon seats at the crossroad between the Sahelian West Africa, Coastal West and the Central Africa (Ministry of Forest and Wildlife, 2007). Being "Africa in miniature", it contains nine, out of the 200 eco-regions in the world, with about 400 mammals' species Unlike most sites in Western Cameroon where wildlife species are found in forests which are under some forms of legal protection such as National Parks, Wildlife Sanctuary or forest reserves, the animals at the LMBM forest landscape are found in communal forests. Under the current legislation in Cameroon, communal forests are those forests outside protected areas which can be converted into any form of land use other than forestry (Ministry of Forest and Wildlife, 2008). As a result, the LMBM forest landscape has in recent decades, witnessed serious habitat fragmentation and hunting leading undoubtedly to precipitous changes in the status of it wildlife species (Asongany and Atem, 2009). It is alleged that the high level of wildlife harvesting in this landscape greatly affects the wildlife population of many 
protected areas in the South-West Region. The LMBM landscape is surrounded by a network of protected areas (Bayangmbo Wildlife Sanctuary, Korupt National Park, Takamanda National Park and the Bakosi national park ), which are set to be linked to each other by this communal forest (unprotected area).

In line with the recommendations from the regional action plan for the conservation of Cross River gorillas throughout the entire Nigeria-Cameroon border landscape, the Environment and Rural Development Foundation (ERuDeF) in 2006, with support from Flora Fauna International (FFI) started the process of building up a community management model at the Bechati-Lebialem forest. A wildlife sanctuary and a wildlife corridor were then proposed in Bechati and Bechati- Mone forest complex respectively. In 2008, report from ERuDeF presented the blue duiker as the most hunted wildlife species in the LMBM landscape and in another socioeconomic report on bush meat trade in the Lebialem area, the blue duiker was presented as the most exploited wildlife species (Juliet and Nancy, 2010). With this trend of exploitation, what has become of the status of this species in the landscape? This work therefore had as objective to generate benchmark data that will serve as a biological indicator for the sustainable management of wildlife in this landscape and it surrounding protected areas. It specifically has to deal with the abundance, geospatial distribution and factors affecting the distribution of blue duikers in the LMBM landscape.

\section{MATERIALS AND METHODS}

\section{Study area}

Located between latitude 606,397.93 $\mathrm{m}-650,762.97 \mathrm{~m}$ and longitude $548,775.33 \mathrm{~m}$ $-621,963.81 \mathrm{~m}$ of the Universal Transverse Mercator (UTM) WGS84N32 Zone coordinate, LMBM landscape is situated towards the Nigeria-Cameroon cross border region in South-Western Cameroon. It covers an area of approximately $1,609 \mathrm{~km}^{2}$ and a perimeter of $225.2 \mathrm{~km}$. (Figure 1).

\section{Methods}

The line transect method (Tsi, 2011) was used for inventory. With a total survey effort of $90 \mathrm{~km}, 30$ randomly positioned transects of length $3 \mathrm{~km}$ each oriented in the East West direction were used in the study. The starting point of each pre-determined transect on GIS map was identified in the field with the aid of a GPS (go to function). While walking on foot, inventory was based on indirect observation of the animals' indices (dung, nest, tracks, food remains and footprints). Nest refers to hide outs, where the animal roost or rest. Signs of human activities encountered were also recorded. The duration of each cue observed was noted as; fresh, old and very old (Fresh $=$ few hours -3 days, Old $=4$ days -1 week and Very old $=$ more than a week).

\section{Statistical analysis}

The encounter rate (ER), the density and total number of blue duikers were estimated using Distance version 3.5. The distance program analysis dung piles as a biological index of presence with the following assumptions (Koster and Hart, 1988)

- Rate of defecation $=4.9$ piles of dung /day (standard error $=0.660$ )

- Duration for decomposition $=18$ to 21 days ( standard error $=0.66$ ).

Spatial distribution maps were produced with the aid of the ArcView program version 3.2. The correlation between ER of blue duiker and anthropogenic activities was done using Statistical version 8.5. The correlation coefficient was calculated using the Pearson's formula: 
$r=[\Sigma \mathrm{XY}-\mathrm{XY} / \mathrm{n}] /\left[\Sigma \mathrm{X}^{2}-\mathrm{X}^{2 / \mathrm{n}}\right]^{1 / 2}\left[\Sigma \mathrm{Y}^{2}-\mathrm{Y}^{2 / \mathrm{n}}\right]^{1 / 2}$

$X=$ Mean ER of animals,

$\mathrm{Y}=$ Mean ER of anthropogenic activities

$\mathrm{n}=$ Number of paired observations

$r=$ Correlation coefficient
It is considered that for the correlation coefficient (r) (Tsi, 2006), When;

$\mathrm{r}<-0.05=\mathrm{A}$ strong negative relation, $-0.05>\mathrm{r}<0=$ A week negative relation, $0<\mathrm{r}<0.05=\mathrm{A}$ week positive relation and $\mathrm{r}>0.05=\mathrm{A}$ strong positive relation.

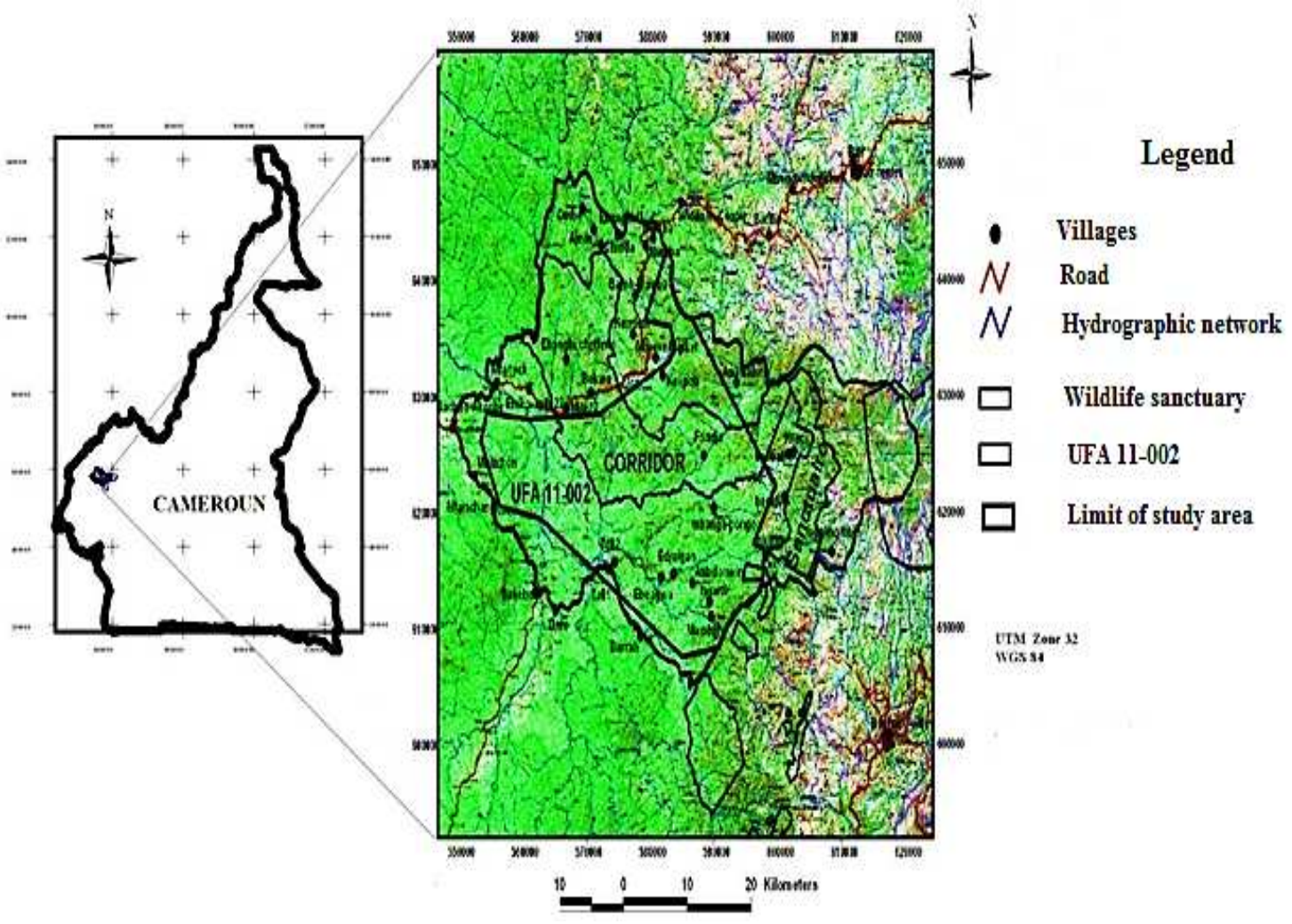

Figure 1: Map of Cameroon showing the location of LMBM landscape and the map of LMBM landscap. 


\section{RESULTS}

\section{Abundance of blue duiker in the LMBM landscape}

The total survey effort was $90 \mathrm{~km}$. Five (05) different biological indices depicting the presence of blue duikers where observed as follows; 101 dung piles, 514 feeing sings, 462 foot prints, 6 nest and 69 blue duiker tracks. An encounter rate of 12.8 indexes per $\mathrm{km}$ was estimated, given a total number of 1162 blue duikers, with a density of 2.51 duikers per $\mathrm{Km}^{2}$ in the landscape (Table 1).

The geospatial distribution of blue duiker in the LMBM landscape

From the distribution map (Figure 2), an uneven distribution of blue duikers was observed in the landscape. The proposed wildlife corridor supported the highest abundance of blue duikers in the landscape, followed by the un-isolated forest patches. In general, the North-West section of the landscape supported a higher population of blue duikers as shown in the distribution map below (Figure 2).

\section{Factors influencing the distribution of blue} duiker in the LMBM landscape

A total of 09 major anthropogenic activities were identified in the landscape; traps, hunting tracks, cartridge shells, oil palm farms, cocoa farm, home gardens to name a few. The Index Kilometric Abundance (IKA) or Encounter Rate (ER) of human activities in the landscape ranges from 0.03 to 1.6 index per km (Figure 3). Based on anthropogenic factors only, the main factors that influence the population and distribution of blue duikers were grouped into two categories; bush meat harvesting and habitat destruction (due to agricultural practices).

From Figure 3, bush meat harvesting is so rampant with an average of about two traps and one cartridge shell observed in every kilometer of transect. Though an average of about one farm, each was observed in every 5 $\mathrm{km}$ of transect, each farm occupies an appreciable potion of forest ranging from 0.5 to 5 ha averagely. This results to a high level of habitat destruction in the landscape.

\section{Correlation between the distribution of blue duiker and anthropogenic activities}

Hunting, especially the presence of cartridge shells was considered as the main anthropogenic factor directly influencing the population of blue duikers; more often than not, a cartridge shell in the forest represents a dead animal (gunshot at an animal). The correlation coefficient $(r)$ calculated between the main anthropogenic activities (Cartridge shells) and blue duiker was $r=0.35$, with a $p$ value of $p<0.05$, and $n=30$. The scatter diagram of the fitted regression line is presented in Figure 4.

The graph in Figure 4 shows the relationship between the ER of blue duikers and anthropogenic activities. The direct proportionality indicates a high population of blue duikers against a background of uncontrolled elevated human activities. Therefore, animal population remains high despite a high level of bush meat harvesting in the landscape. 


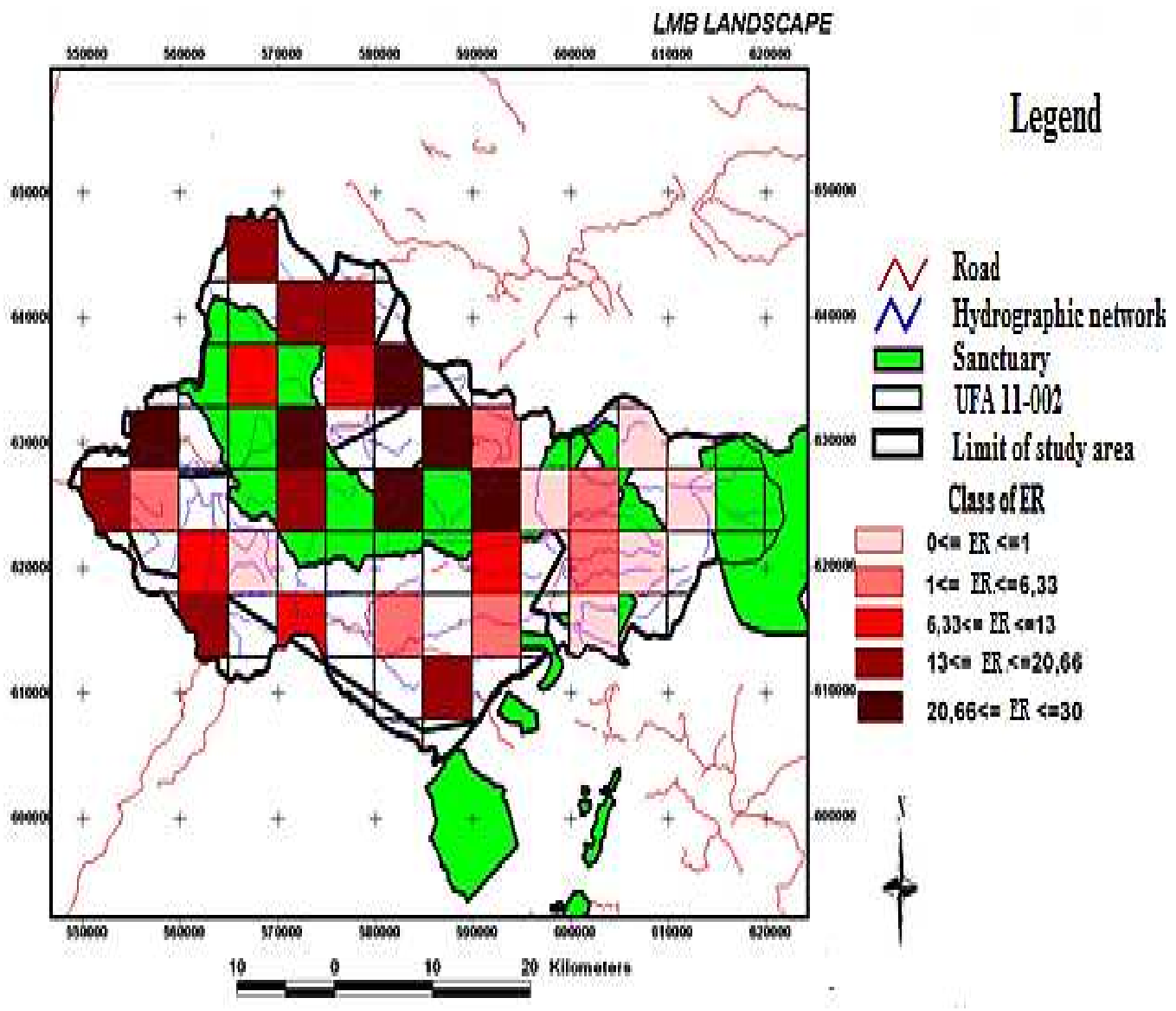

Figure 2: Map of LMBM landscape showing spatial distribution of blue duiker within the rainy season.

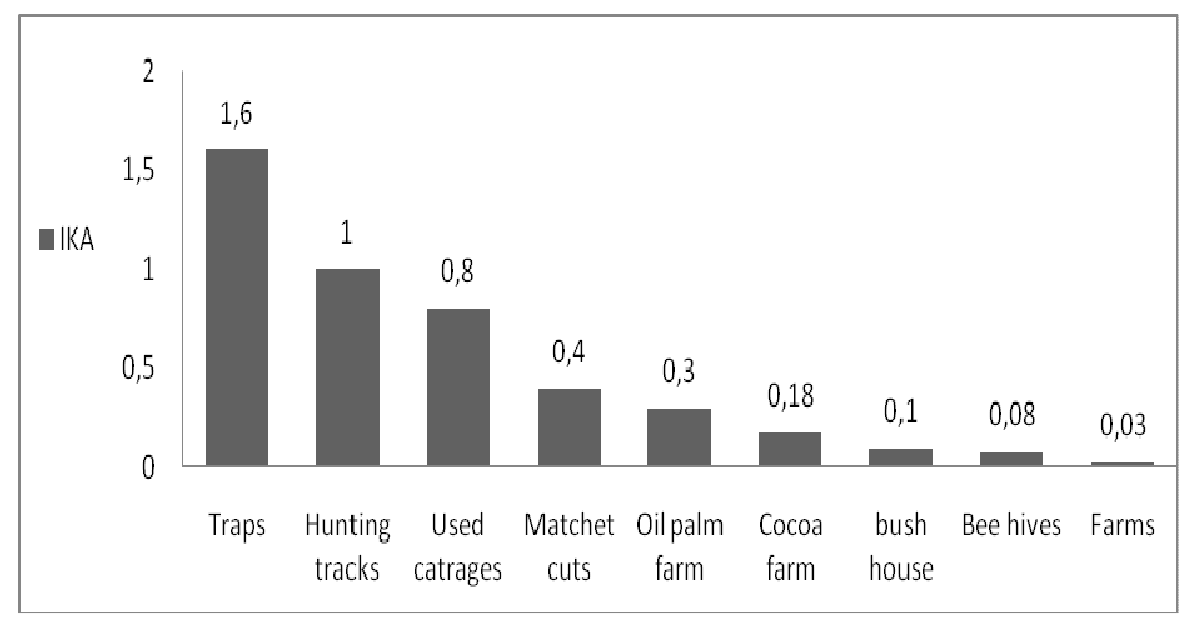

Figure 3: Relative abundance of anthropogenic activities in the LMBM landscape. 


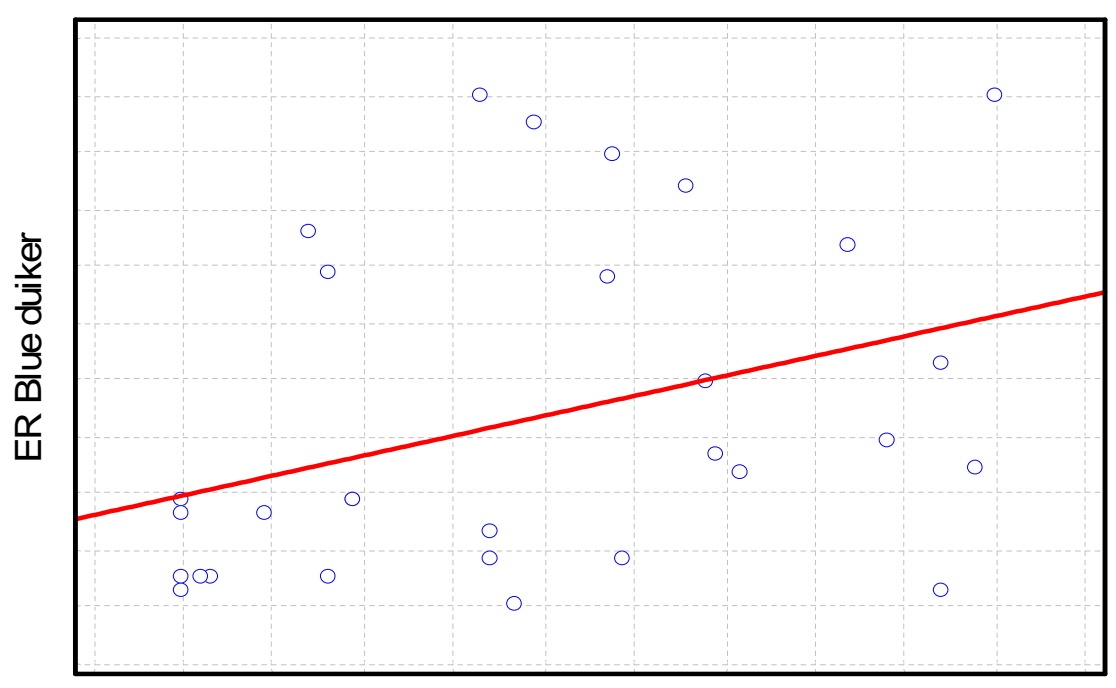

ER Human activities

Figure 4: A scatter diagram showing the fitted regression line of pooled encounter rate of blue duiker and anthropogenic activities in the LMBM landscape.

Table 1: Density and effective number of Blue Duikers in the LMBM Landscape.

\begin{tabular}{lcccc}
\hline Parameter & $\begin{array}{c}\text { Estimate } \\
\text { individuals } / \mathbf{k m}^{\mathbf{2}}\end{array}$ & $\begin{array}{c}\text { Coefficient } \\
\text { of variance } \\
(\boldsymbol{\%})\end{array}$ & $\begin{array}{c}\text { Degree of } \\
\text { freedom (df) }\end{array}$ & $\begin{array}{c}\text { Confidence } \\
\text { interval at 95\% } \\
\text { significant }\end{array}$ \\
\hline Density & $\mathbf{2 . 5 1}$ & 30.46 & 98.05 & $1.39-4.53$ \\
Number & $\mathbf{1 1 6 2}$ & 30.46 & 98.05 & $644-2099$ \\
\hline
\end{tabular}

\section{DISCUSSION}

The LMBM forest landscape is not a protected area, but a communal forest which can be converted into any form of land use other than forestry under the current legislation in Cameroon. The findings above show that there is currently a high level of bush meat harvesting and a tragic forest transformation due to uncontrolled human activities in the landscape. From Figure 3 above, though Farms (oil palm, cocoa, and home gardens) represents a smaller proportion of anthropogenic activities on the bar chard, this activities have far greater potentials in contributing towards habitat destruction. A similar situation of habitat destruction had earlier been reported in the South-West Region by Asongany and Atem (2009) and. Tsi and Ngundem (2010). It is therefore clear that unlike protected areas, most communal forest areas in the South-West Region of Cameroon are under the same threat of high uncontrolled habitat destruction. Consequently, wildlife species are suffering a drastic population decline. Tsi and Ngundem made the same observation in 2008.

Despite the drastic decline of wildlife population resulting from poaching and aggravated habitat destruction in the SouthWest Region in general, the density of blue duikers estimated in the LMBM landscape remains unexpectedly very high, relatively (2.51duikers per $\mathrm{Km}^{2}$ ). When compared to the findings of Walhert et al. (1999-2000 = 1.9 duikers per $\mathrm{km}^{2}, 2000-2001=1.8$ duikers per $\mathrm{km}^{2}$ and 2001-2002 $=2.2$ duikerss per $\mathrm{km}^{2}$ ) in Korupt National Park, 
the estimated density in the LMBM landscape is high for a non protected area. Many reasons account for this unexpected high density observed.

It is indicative of a high resilience in the population of blue duikers in the landscape against a background of uncontrolled elevated human activities especially poaching. Also, since LMBM landscape is surrounded by a number of protected areas (Bayangmbo Wildlife Sanctuary, Korupt National Park, Takamanda National Park and the Bakosi national park), it was observed that animals from these protected areas constantly move into and through the LMBM landscape. This confirms an earlier suggestion that the LMBM landscape serves as a wildlife corridor linking the surrounding protected areas (ERuDeF, 2006). This high duiker density is therefore a strong evident to support the creation of a wildlife corridor in the LMBM landscape as a protected link between the surrounding protected areas.

It cannot be denied therefore that, despite the stringent protective measures taken to protect wildlife species in the surrounding protected areas, Government's effort seems futile due to a loophole through this natural unprotected corridor. Animals are therefore constantly hunted in the LMBM landscape as they move through from one protected area to another as depicted by the high positive correlation coefficient $(r=0.35)$ and the direct proportionality in the relationship between anthropogenic activities and duiker encounter rate (Figure 4).

\section{Conclusion}

The high population of blue duikers against a background of uncontrolled elevated human activities in the LMBM landscape serves as a biological indicator. It is indicative to the constant endangerment of animals as they move from the surrounding protected areas into and through this unprotected area.
This is a strong evident to support the gazetment of the proposed Bechati wildlife sanctuary and the proposed Bechati- Mone wildlife corridor situated in the LMBM landscape. Furthermore, these findings go a long way to confirm the Recommendations of the regional action plan for the conservation of Cross River Gorillas and other big game species throughout the entire NigeriaCameroon border landscape through a network of protected areas linked by wildlife corridors (ERuDeF, 2006).

\section{ACKNOWLEDGEMENTS}

Special thanks to G.I.E University of Dschang, Environment and Rural Development Foundation (ERuDeF) and Flora Fauna International (FFI) who in collaboration funded the data collection process.

\section{REFERENCES}

Asongany F, Atem E. 2009. Socioeconomic Report of the Tofala-mone forest corridor. The Environment and Rural Development Foundation (ERuDeF) Buea, South-West Region, Cameroon.

Dunn A, Okon D. 2003. Monitoring the abundance of diurnal primates and duikers in Korup National Park, Cameroon 2001-2003. Unbublished Report. Korup Project, Mundemba, Cameroon.

Juliet, Nancy. 2010. Hunting and trapping in Lebialem Division, Cameroon. Int.Res.Com., 11: 01-12.

Koster SH, Hart JA. 1988. Methods of estimating ungulate populations in tropical forests. African Journal of Ecology, 26:117-126.

Lee White, Ann Edwards. 2007. Conservation des forêts pluviales Africaines manuel des méthodes de recherché.

Ministry of Forest and Wildlife 2007. The wildlife law as a tool for protecting threatened species in Cameroon, 34p. 
Ministry of Forest and Wildlife. 2008. Management Plan for the Korup National Park and its Peripheral Zone $138 \mathrm{p}$.

Nguedem S, Tsi E. 2010. Abundance and distribution of large mammals of the Bakossi landscape area, South-West region Cameroon. Journal of Soil Science and Environmental Management, 2(2): 43-48.

Tsi EA. 2006. Status of wildlife and its utilization in Faro and Benoue national park north Cameroon: Case study of the Derby Elands Taurotragus derbianus and African Wild Dog Lycaam pictus, Ph.D thesis Bradenburg University of Technology Cottbus, Germany, 149p.

Waltert M, Sol H, Simone R. 2006. Estimate of blue duiker (Cephalophus monticola) density from diurnal and nocturnal line transects in the Korup region, southwestern Cameroon. Von-Sielbold-Str. 2, 37075.

Willcox AS, Nambu DM. 2007. Wildlife hunting practices and bushmeat dynamics of the Banyangi and Mbo people of southwestern Cameroon. Biological Conservation, 134: 251-261. 